\title{
Mental and Psychological Structure of Personality in the Context of the Figurative Language of Art
}

\author{
Tatiana Leshkevich \\ Southern Federal University \\ Rostov-on-Don, Russia \\ Leshkevicht@mail.ru
}

\author{
Anna Motozhanets \\ Southern Federal University \\ Rostov-on-Don, Russia \\ annamt@bk.ru
}

\begin{abstract}
The article justifies the method of comprehending the mental and psychological structure of personality through the analysis of a concept-sphere reflected in the language of art. Special focus is placed on the hypothesis according to which fictional plots (Orpheus, Prometheus, Odysseus, Faust) are viewed as reflections of fundamental human behavior patterns, which determine personal choices, establish a specific personal-eventive ontology and are reflected in the language. Particular attention is given to one of the advantages of Art, namely the ability of Art to translate experience transempirically. The artide demonstrates the attractive nature and practice-behavioral orientation of an artistic image and assumes that it has a potential of emotional reasoning. Special emphasis is put on intonational nature of speech (B. Astafyev), as a specific mechanism of effecting a psycho-mental structure of personality. The authors refer to the concept of chronotope (A. Ukhtomsky, M. Bakhtin) to reveal the mechanisms of intellectual enrichment by which an individual is plunged into the world of fiction and encounters the Face of the Other, whereas emotional response is viewed as a quality criterion with regard to the work of art.
\end{abstract}

Keywords-personality; language of art; transempirical translation of experience; intonation; chronotope

\section{INTRODUCTION}

The influencing potential of Art with regard to a person's psycho-mental sphere and his system of values remains a subject of much controversy. However, a work of art has been always viewed as a means of penetrating into a person's inner world, comprehending his individuality and motivations, shaping his worldview and value paradigms. The ability to reflect reality through emotional figurative language, as well as the influencing potential of fictional chronotope and a specific suggestive component (imposing psychologically relevant information) are among the features, which distinguish Art from other forms of collective consciousness.

\section{A JOURNEY INTO THE DEPTHS OF CONSCIOUSNESS}

Art was traditionally believed to provide a man with the way to self-cognition, the genuine knowledge of reality and human relations through emotions and the language of imagery. Fiction plots are assumed to reproduce fundamental patterns of human behavior. For instance, Orpheus,
Prometheus, Odysseus, Faust plotlines shape human choices and worldview establishing a specific personal-eventive ontology. Scholars involved in psychoanalysis view these plotlines as archetypical recurring patterns of human experience. In this regard, we may speak of an individual's proclivity for this or that behavior patterns. We might also assume that a work of art appears to be a specific reconstruction of a person's inner world with its attitudes and orientations. Its influence on a person's mentality depends on his perceptivity and the extent to which he is able to comprehend the work of art. According to E. Feinberg, embedding in human mind ideas, rules and norms, which can't be logically reasoned but are necessary for survival, is a "superfunction" of Art [1].

Thus, Art and artistic image as its main category can be viewed as a concentration of human psychoemotional resources, with artistic image being a unique combination of distinctness and generality, the individual and typical, the spontaneous and regular. A figurative language of art possesses an attractive power, which is explicitly practiceand behavior-oriented due to the fact that an artistic image is capable of comprising behavior patterns.

Being the basic unit of Art, an artistic image contains the resources of emotional reasoning, is capable of provoking a strong emotional response. By doing so, an artistic image claims to be a universal language and its expressive potential stands against the lost value of words.

However irrational emotional perception is, its impact is great. It is worth mentioning here that Old Indian aesthetics distinguished between nine basic emotions: love, joy, surprise, sadness, discontent, indignation and finally, tranquility, sublime spirit and aloofness. With each emotion containing 33 shades, the total amount ran into 297 types of emotions [2]. As a rule, this hierarchy is polarized, whereby love is opposed to hatred, happiness to grief, joy to sadness, enthusiasm to disappointment, with its artistic interpretation being the opposition of the epical to the lyrical. The former focuses on events, while the latter is devoted to feelings. Binary oppositions seem to be integrated into the structure of fictional reality, comprising harmony and disharmony, the ugly and the beautiful, tragedy and comedy, facts and fiction. Attracting attention, keeping attention and shifting attention to the meanings contained in the artistic work are the magic properties of Art. 
The artistic worldview reconstructs human life in detail up to borderline states, highlighting the most sinister dimensions of human nature in their true colors. It is not for nothing that one of the most effective linguistic stylistic devices is hyperbole - exaggeration - also capable of depicting human pathology. The phenomenon of anti-art, revealing and explicating unconscious instincts, proves that there are destructive forces embedded in human mind and determines the extent of emotional ill-being. A work of art sets up and reflects human behavior patterns which in their turn play an essential role in shaping our preferences and further perception of a fictional text.

Special attention should be given to a specific mental state known as "double-track experience" which occurs under severe stress when a person's past experience turns into an emotional context accompanying his perception of the current moment. Thus, the past is stretching to a person's present arousing regret and remorse. As the result, the attention focused on the work of art can transform a person's inner world.

Intonation as a tool of reflecting reality through sounds plays a crucial role both in art and communication [3]. A voice signal as a basic fundamental kind of signals is characterized by pitch, volume level and tone color. A combination of sound and intonational effects conveys additional information and takes part in shaping meanings. Intonational nature of sound appears to be a specific mechanism of effecting psycho-mental structure of personality capable of codifying and providing emotionally colored information. Semantic potential of intonation comprises a whole world of human feelings and relations. Moreover, intonation can be viewed in relation to national spirit, whereas intonation contains invariable characteristics testifying to psychological makeup of ethnicity. In this context we can consider language, intonation and meaning as interrelated components of influence effecting one another.

According to the Ancients, perceptual experience of outstanding works of art is accompanied by catharsis with further mental purification and illumination. Catharsis was originally thought to be connected with musical sounds, with Pythagoras viewing melodies and musical rhythms as a remedy for body and mind. However, the catharsis effect was later extended to the influencing potential of Art as such. In his "Poetics" Aristotle develops a concept of catharsis generated by tragedy. Aristotle assumes that the function of tragedy is to arouse pity and fear, to wake a man up to sufferings, to bring them to the open, which then leads to purification and pacification. All the above-said leads us to the conclusion that intensity of emotions aroused by the work of art can be viewed as its quality criterion.

\section{TRANSEMPIRICAL TRANSLAT ION OF HUMAN EXPERIENCE}

Art reconstructs numerous life stories - comic and tragic, lyrical and mundane - creating different realities in a figurative fictional form. By empathy and concern for the fate of fictional characters and dramatic situations, a person gets involved in the reality and human relationships reflected by a figurative language of art. By doing so, Art provides a transempirical translation of human experience. In a general way, it means that individual's mind is carried away by a work of art to the imaginary world of relationships. A work of art encodes a whole range of emotional experiences and enables a person to live through a great variety of situations impossible for him to experience in real life due to the finitude of his own existence. Fictional plots are decoded by the mind of a recipient, get engraved in me mory and strongly influence a person's psycho-mental sphere. Thus, a man gains a specific personal experience transempirically, i.e. without real-life experience of similar situations. A person's existence is supplemented with a superstructure containing various experiences provided by a treasure house of art.

Transempirical translation of experience contributes to significant changes in a person's mind and personality structure. Empathy, which accompanies the perception of a work of art, enhances integration of all levels of one's psycho-mental sphere, which leads to shaping new life strategies, making quality choices, rethinking past experience.

Transempirical translation of experience by virtue of the language of art appears to be an essential mechanism of personal development and generating new information. Providing a person with additional experience, it expands the semantic continuum of his psycho-sphere, broadening it beyond stereotypes and conventions. By virtue of transempirical experience a man finds alternative ways to address the challenges of the real world.

Moreover, transempirical translation of experience testifies to the principle of information acceleration, which in this case is based on expanding the "emotional range". Scholars believe practically any perception of sensory information to be connected with integration of signals [4]. The "discovery" of a work of art starts by a generalized simplified perception, while a detailed insight into minor nuances can be gained through multiple reference [5]. Sympathy for the past generations and empathy for the present give rise to a specific emotional energy. A true work of art leaves an indelible imprint on the souls of both the author and the recipient, effecting self-expression and selfidentification. We may speak of Art as a modeling laboratory for life strategies on a psycho-emotional level. According to some scholars, artistic experience "tunes in" the mind to penetrate fictional worlds with their own rules by free will, thus providing anticipatory, prognostic and modeling functions, which play an essential role in reshaping one's own worldview [6].

Esthetic pleasure coupled with empathy and transempirical experience are among the most essential advantages of the figurative language of art.

\section{METHODOLOGICAL STRATEGY}

The main methodological approach to studying mental and psychological components of personality structure by means of figurative language of art is a genealogical approach, which consists in referring to the origins of artistic patterns with due regard to value paradigms of different epochs. The interpretation method is also of great value as it 
helps reveal and explain the semantic layers of the work of art and specific features of artistic image. Particularly essential is the principle of socio-cultural determination which relates the work of art to a particular epoch, ethnical and socio-cultural specificities.

The complementarity principle revealing the interconnection of imagery and idea, the individual and typical, the epical and lyrical is also given consideration. The categorial pairs reflecting the dialectic relation of form and content, essence and phenomenon, subject and object appear to be important methodological instruments as well.

With Art being a complex, open-ended, non-linear system, a synergetic approach seems to be an effective method of analysis, within which Art is viewed as a zone of attraction. Both comprehensive and synergetic approaches enable us to reveal fundamental characteristics and functions of Art with regard to the author with his intentions, the means of expression and up to the recipient. The principle of integrity is a fundamental methodological tool.

\section{THE ADVANT AGES OF THE LANGUAGE OF ART AND ARTIST IC WORLDVIEW}

From the neurophysiological standpoint, the essential advantage of art consists in the fact that it makes extensive use of the right-brain which is responsible for processing mu lti-meaningful contexts. By doing so, Art relies on diverse mechanisms of exploring the world including intuition, association, imagination rather than looking for universal rational tools. Art is capable of enhancing a person's sensibility through empathy for the happenings of the past, continually revealing new essential meanings. The openended nature of Art contributes to generating multiplicity of interpretations due to peculiarities of personal perception. Life-purpose semantic component of a true work of art is made vivid and presentative and then perceived by the whole human being.

Another advantage of Art consists in the fact that it enables a person to break away from the mundane, to go beyond the present moment.

According to the classic idea of kalokagathia (from Greek "nobility, goodness"), beautiful means noble and vice versa. However, the question of what beautiful is and what its origins are remains a controversial is sue. Plato relates the real beauty to the intelligible world of ideas penetrating an artist's soul. The quest for an ideal beauty in nature has always been a characteristic feature of realism. But while classical realism targets at observing nature, socialist realism gave rise to a debate between the so-called natureists (prirodniki) and societalists (obscestvenniki). The former insisted that beauty be sought in nature, while the latter argued in favor of social background of beauty, the relation of art to social and cultural environment. The idea of art for art's sake was opposed by another extreme of the utilitarian approach to art, according to which art was seen as entertainment. And finally, art in the service of ideology became the means of propaganda.
The tradition of assigning lawmaking power to the beautiful goes back to Kant and further on to Russian philosophers. Indeed, the world's harmony must be reflected in the structure of human life. In this respect, the aesthetic can play the role of a paradigm setup. Being one of the criteria of an academic research, the aesthetic element indicates the ambition of science to reconstruct the world in its entirety [7].

It should be mentioned that a work of art appears to be an open-ended system, conveying the concept-sphere and energy impulses. A work of art is capable of constructing an information model or a model of probable future. The figurative language of art performs a function of artistic prevision by reflecting the anticipations of the forecoming future and synchronizing non-simultaneous events. Figurative language of art expresses emotional attitudes to a range of probabilities offering a certain vision of the future. Thus, a pers on is provided with an opportunity to visualize his choices, while the world appears to be a "museum of imagination".

Art is believed to be a specific encyclopedia of humanology, therefore, there is a need for a vast audience of experienced recipients making up an additional sphere of information and energetic interconnection with aesthetic meanings and behavior patterns generated by art.

\section{CHRONOT OPE AND THE CATEGORY OF "FACE"}

While studying the mechanisms of effecting a person's psycho-mental sphere by art, we should refer to the essentail notion of chronotope (A. Ukhtomsky, M. Bakhtin), which creates a space-time continuum of human relationships and defines cultural-historical meaning of events. Chronotope is not a mere unity of space and time but rather a keen sense of this unity, by which one gets sucked into an emotional whirlpool. The attraction of cultural and historical events reflected by the figurative language of art adds significance to the notion of chronotope.

As we have stated before [8], the notion of chronotope was introduced to psychology and neurophysiology by A. Ukhtomsky as the dominant element of consciousness, which induces certain behavior in particular situations. According to A. Ukhtomsky, a personal-psychological aspect of chronotope consists in the fact that by reconstructing the atmosphere of someone's existence chronotope enables us to see the Face of the Other, "to see and get to know Socrates and Spinoza", who come to light and are getting closer to the recipient. Thus, A. Ukhtomsky introduces the category of Face, existing in historical time. According to Ukhtomsky, Face is a living, concrete and integral unity, striving to make a unique contribution to the world history, and therefore is highly responsible and exacting [9] .

At present the category of Face seems to be in great demand [10]. However, in his time the scholar came to a conclusion that this category was not given due regard by philosophy, logic, and the theory of cognition. Ukhtomsky claimed the need to focus on the Face of the Other, to shift the attention to something external to one's own self, to be 
able to put oneself in another person's shoes. According to Ukhtomsky, a person's spiritual life is determined by a dominant idea as a specific form of causality. A creative dominant takes root in the mind of a scholar or a writer and directs his activity. As opposed to logical-geometric approach to learning life, A. Ukhtomsky emphasized the relevance of physio-psychological factors in the process of creating its integral image. Besides the unity of time and space, chronotope testifies to the close linkage between man's as pirations and spatio-temporal context.

Through the analysis of M. Bakhtin's concept of chronotope [11], we get an insight into spatio-temporal characteristics reflected in literature studies and aesthetics. M. Bakhtin considers chronotopes which define genre and generic distinctions, and date back to antiquity. The author distinguishes between three types of novel-epic chronotopes: the adventure chronotope, adventure-everyday chronotope, and the chronotope of biography. Emphasizing the relevance of chronotope for literary analysis, Bakhtin realized the broad potential of this concept in general. It should be noted here that depending on the type of relation to time and space we can distinguish between temporal arts (like music), dimensional arts (like painting and sculpture), and temporaldimensional arts (literature, theatre). We can speak of the cultural chronotope of the Ancient East, the Ancient Greece, the chronotope of Christianity, the Renaissance, etc., each revealing the dominant values of the epoch. The chronotope of a fictional world "adds value" to time by revealing the specificity of a personal worldview [12] coupled with the unique context of historical, cultural and ethnical meaning of time and space. Within this mode of existence the value of cultural meanings are closely connected to the intentions of soul.

Most importantly, emotional experience and meanings become visualized and have an illustrative nature. The world of characters, the author's intentions and the recipient's perception intermingle creating a specific spatio-temporal meaningful unity, giving rise to spiritual togetherness. Although we used to think that humans experience space and live through time, the concept of chronotope has revealed the value of a spatio-temporal image of an epoch. We emotionally experience time due to its finitude, however, we also experience landscapes and styles of past epochs, which channels human thoughts and energy. Architectural concepts of the city is a sphere of human activity as well as the samples of some epoch. Particular spacing is capable of setting the mood: either festive or somber. Living space, working space, recreational space all contain the emotional component. Chronotope appears to be a projection of intertwined time and space as integral part of historical events onto the spiritual dimension of our human experience.

\section{CONCLUSION}

All the above-said leads us to the following conclusions. With a human being unable to live through the whole variety of life-situations, Art becomes responsible for transempirical translation of experience. Given its modeling and prognostic functions, transempirical experience is an essential mechanism of personal development, capable of pushing the boundaries of human existence.

The figurative language of art both reflects personality structure and shapes basic patterns of human life.

The artistic chronotope is a tool of reconstructing the emotionally colored spatio-temporal image of an epoch, which enables the recipient to live through characters' experiences. The intensity of emotions can serve as a criterion for evaluating the figurative language of art.

\section{REFERENCES}

[1] E. L. Feinberg, Two Cultures. Intuition and logic in art and science, M., Nauka, 1992.

[2] S. I. Tyulyaev, Indian Art, M., 1968, p. 64.

[3] B. V. Astafyev, Musical form as a process, M., Muzyka, 1971.

[4] V. P. Ryzhov, Information aspects of self-organization in art in Synergistic paradigm. Nonlinear thinking in science and art, M., Progress-Tradiciya, 2002, p. 160.

[5] Ibid. p. 161

[6] E. G. Levchenko, Practices of contemporary art in the system of postnonclassical practices in Post-nonclassical practices: the experience of conceptualization, SPb, MIR, 2012, p. 474.

[7] T. G. Leshkevich, Philosophy of science, M., Infra-M, 2014, p. 99.

[8] T. G. Leshkevich, The categories of time, space, chronotope in social and humanitarian knowledge" in Philosophy of science, Rostov-onDon, Fenix, 2006, pp. 285-300.

[9] Ibid. p. 299.

[10] O. V. Chistyakova, Self and other in the communicative space of the global world // Proceedings of the 2017 2rd International Conference on Contemporary Education, Social Sciences and Humanities, (ICCESSH 2017). Advances in Social Science, Education and Humanities Research. Moscow, June 14-15, 2017. Paris: Atlant is Press, 2017, pp. 6-11.

[11] M. M. Bakhtin, Forms of time and chronotope in the novel in Questions of literature and aesthetics, M., Hudozhestvennaya Literat ura, 1975, pp. 234-407.

[12] A.A. Motozhanets, Actualization of the grammatical category of Time in fictional narrative in Contemporary state and perspective vectors of development in philology, linguistics, language studies and communication science, Rostov-on-Don, Nauchnoe Sotrudnichestvo, 2014, pp. 100-132. 